\title{
A SEXUALIDADE COMO PATRIMÔNIO PESSOAL E CULTURAL: UMA PORTA ABERTA POR MARABÁ DE AMOEDO NA PERSPECTIVA DO MUSEU COMO ESPAÇO EDUCATIVO E INTERCULTURAL
}

RESUMO: O presente estudo teve como mote a análise crítico-interpretativa da obra Marabá, de Rodolpho Amoedo, com foco na compreensão da maneira como o corpo feminino sexualizado agregou representações simbólicas do imaginário sociocultural brasileiro do século XIX com suas projeções e seus desdobramentos nas relações entre educação, sexualidade e interculturalidade nos sujeitos contemporâneos. Neste sentido, objetivou-se compreender o papel da sexualidade imbricada à mestiçagem como construtora de sujeitos sexuais a partir da educação não-formal realizada nos museus, bem como realizar a leitura do corpo sexualizado de "Marabá", partindo da ideia de um etnoconhecimento para o etnorreconhecimento, situar, interculturalmente, a obra musealizada "Marabá" no contexto da educação do corpo pelo patrimônio pessoal e sociocultural. Pesquisa de natureza qualitativa, tendo como técnica de coleta de dados "Grupo Focal". Para análise privilegiou-se concepções semióticas para se ler a obra pictórica "Marabá" de Rodolpho Amoedo no campo de Museu e Patrimônio. Concluiuse que, através dos respondentes do Grupo Focal, o corpo feminino e sexualizado foi reconhecido como patrimônio pessoal e sociocultural, tendo a mestiçagem aliada à sexualidade como marca identitária mais contundente que confere ao corpo mestiço o valor de patrimônio mais genuíno e relevante da nação brasileira

PALAVRAS-CHAVE: Sexualidade. Educação. Museu. Patrimônio. Interculturalidade.

\footnotetext{
${ }^{1}$ Doutora em Ciências em Museologia e Patrimônio. UNIRIO - Universidade Federal do Estado do Rio de Janeiro. Rio de Janeiro - RJ - Brasil. 22290-240. Coordenadora Pedagógica. UNIG - Universidade Iguaçu. Itaperuna - RJ - Brasil. 28300-000. Pesquisadora, colaboradora. FAETECRJ - Instituto Superior de Educação de Itaperuna. Itaperuna - RJ - Brasil. 28300-000 - margarete@ zartex.com.b

${ }^{2}$ Doutora em Educação. UFF - Universidade Federal Fluminense. Niterói - RJ - Brasil. 24220-900. PósDoutorado em Ciências da Educação e Professora associada e pesquisadora do Programa de PósGraduação em Museologia e Patrimônio. UNIRIO - Universidade Federal do Estado do Rio de Janeiro. Rio de Janeiro - RJ - Brasil. 22290-240 - asouzareis@ hotmail.com
} 


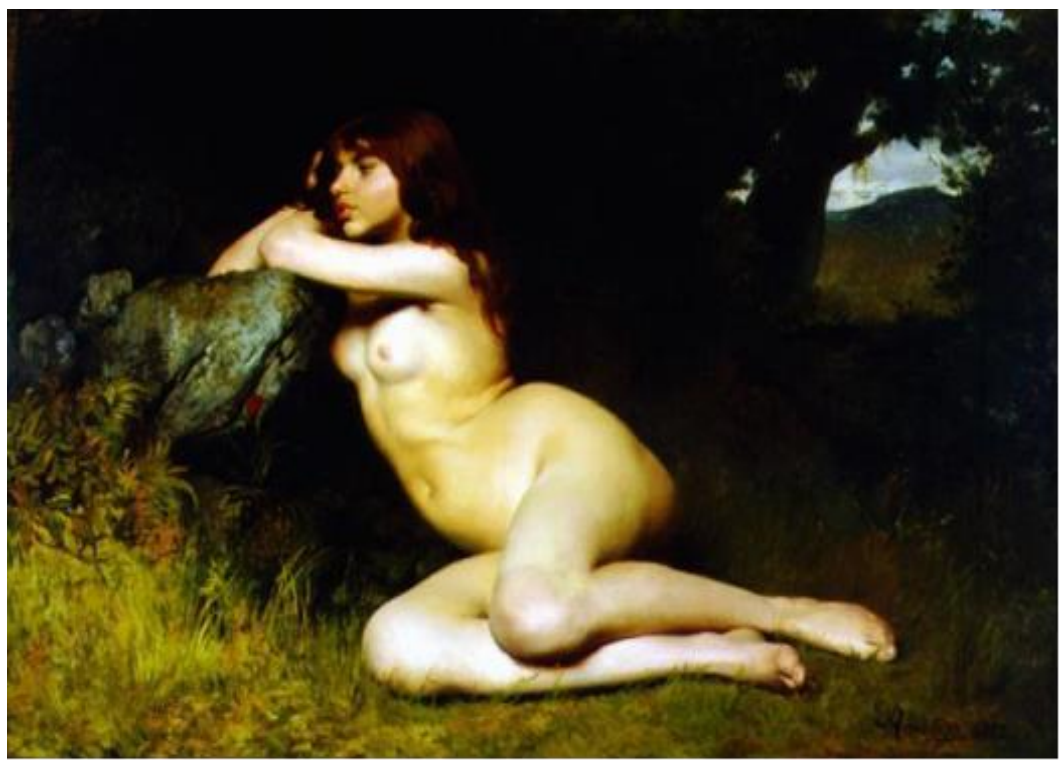

AMOEDO, Rodolfo. Marabá. 1882. 1 original de arte, óleo sobre tela, $120 \mathrm{~cm} \mathrm{x} 171 \mathrm{~cm}$. Pintura pertencente ao Museu Nacional de Belas Artes, Rio de Janeiro.

\section{INTRODUÇÃO}

Durante a jornada da vida humana, a educação, da qual a trajetória é resultante da relação de sua interdependência entre o social e a cultura, proporciona ao indivíduo um olhar sobre si, na medida em que se (re)constrói o conhecimento no campo do Outro, ou seja, o resultado da educação se dá graças à presença dum outro (SALTINI, 1998).

Nessa linha de raciocínio, Reis e Pinheiro (2009) postulam reflexões, ressaltando que a história dos cotidianos, presente na educação formal e não formal, tem indicado que por ela circulam discursos de diferentes matizes, e que esses variam por sua natureza, de acordo com os ventos políticos que sopram em cada momento histórico.

O reconhecimento das autoras acerca das variáveis, em se tratando de locus de aprendizagens, valida o intento deste estudo sobre o corpo como patrimônio pessoal e cultural no campo do saber da Museologia e do Patrimônio, uma vez que, como fenômeno cultural com suas diferentes representações, em distintos tempos e espaços, "[...] museus em nossa contemporaneidade, face aos grandes avanços da técnica, da ciência e da arte, têm diante de si uma grande responsabilidade: repensar sua identidade sociocultural" (REIS; PINHEIRO, 2009, p.2).

Nesse contexto, Reis e Pinheiro (2009, p.2) traduzem a museologia como

[...] instância organizada do saber humano como campo científico, cabe-nos circunscrevê-la, também, entre os meios comunicacionais em que a educação, entendida como prática social, se inclui como uma 
de suas interfaces, restando-nos reforçar que a educação é comunicação em ação e em processo por estabelecer-se em uma dialogicidade presumida em sua existência fundante entre os humanos.

Defende-se aqui a ideia de que a construção do saber humano é algo dinâmico cuja capacidade inata de aprender encontra-se imbricada nos signos contidos na tessitura da história humana, nos labirintos das simbologias a que elas o remetem quando ele descobre que está imerso num processo de aprendizagem ilimitada na construção de sua trajetória, sobretudo de sua identidade e subjetividade.

Feito o preâmbulo, recorre-se a Scheiner e Soares (2010) para sublinhar a relevância desta pesquisa no palco da Museologia, pela possibilidade de despertar o olhar inter, multi e transdisciplinar e intercultural, como referenciais importantes para a formação educacional do ser humano.

Igualmente, persegue-se a oportunidade de compartilhar e aprofundar conhecimentos acadêmicos, através do entendimento de que a Museologia abre portas para o (re)conhecimento de valores que compreendam, desde a esfera pessoal, social, até o conjunto de recursos vinculados às relações que cada sociedade estabelece com o meio natural e/ou com sua memória cultural e patrimonial como expressão do conjunto de experiências e saberes acumulados pelo humano, no tempo e no espaço, a ponto de viabilizar a valorização de aprendizagens sobre corpo e da sexualidade como patrimônio cultural. Para tanto, tem-se como meta a promoção da solidariedade e da tolerância entre as culturas, o respeito à diferença e o diálogo intercultural, bem como ampliar o olhar sobre a práxis educativa.

Alicerçada nos preceitos de uma educação emancipatória, cujo cenário é constituído pelo legado histórico, os museus, segundo Reis e Pinheiro (2009, p.2), são entendidos mais recentemente como

[...] um serviço público e centro de investigações e estudos dos mais complexos e variados, [que] trazem em si mesmos a necessidade de transformações e inovações que passam pela pedagogia e pela didática de ensino, a fim de servirem como eixo transversal a ser impresso em todas ações museísticas, bem como a necessidade de formação educativa de todos os profissionais que por ali circulam com suas práticas específicas.

No ensejo de poder colaborar no campo do conhecimento com novos olhares sobre Patrimônio, o foco deste estudo ancora-se na "Museologia e no Patrimônio" como área de concentração para esta pesquisa, visando a compreender de que forma o corpo 
humano pode atuar como depositário das implicações sociais e culturais de uma dada época, trazendo como questão-problema: em que medida o corpo nu feminino e mestiço flagrante na obra musealizada "Marabá", de Rodolpho Amoedo, pode ser interpretado trazendo à tona questões identitárias e históricas presentes nas relações entre educação, sexualidade e interculturalidade, quando analisadas a partir das representações simbólicas do Brasil oitocentista e sua ressonância na cultura contemporânea?

Refletindo-se a respeito dessa rede de relações, Santos (2008, p.129) assim elucida:

\begin{abstract}
A Museologia e a Educação, consideradas como histórico-socialmente condicionadas, assumem em cada período histórico características que são fruto das ações do homem no mundo, fazendo com que possamos considerá-las como possibilidade e não como determinação. Daí a necessidade de contextualizá-las situando-as no tempo e no espaço, compreendendo-as como ação social e cultural. [...] cultura e desenvolvimento, mais do que nunca, têm de andar de mãos dadas.
\end{abstract}

Para elucidar o pensamento mencionado, a título de melhor fundamentar o olhar museológico sobre o real, salienta-se que a França dos anos 60, alicerçada nos preceitos de crenças, valores e representações, serviu de nascedouro para a História das Mentalidades, cuja engrenagem histórica transcrevia o que permeava e o que escapava aos sujeitos sociais, por permitir revelar o conteúdo impessoal do seu pensamento.

À luz do pensamento de Baczko (1984), o imaginário produz valor significativo sobre as esferas política e social. Portanto, através das imagens criadas de si, em uma dada época, que numa sociedade manifestaria e/ou ocultaria suas reais intenções e o lugar que lhe caberia naquele contexto histórico.

O termo imaginário/imaginação possui um sentido polissêmico e, ao adjetivar com social, a quase imprecisão seria adicionada ao conceito. Assim, a noção de Imaginário Social foi assim postulada: "trata-se de aspectos da vida social, da atividade global dos agentes sociais, cujas particularidades se manifestam na diversidade do seu produto".

O imaginário social se concretizaria, então, através da construção dos discursos. O imaginário se consolida no campo do simbólico, mas a atribuição do símbolo não se resume em constituir uma classificação, mesmo que possua como sua função inserir valores, aperfeiçoando, assim, o comportamento dos indivíduos e da coletividade (BACZKO, 1984). O imaginário social, indubitavelmente, é construído por 
contingências históricas (tempo, espaço, cultura etc.), as quais interferem sobremaneira na leitura contemporânea de todos os acontecimentos em tempo real.

A título de provocação acadêmica, a relevância deste estudo, no âmbito da Museologia, está na releitura da "Marabá" de Rodolpho Amoedo, exposta no Museu Nacional de Belas Artes no Rio de Janeiro - Brasil, a fim de reafirmar o museu como lugar de vida, que registra todas as experiências da humanidade. Dessa forma, o corpo, pela ótica do museu, é tomado como marca identitária, permitindo contar, recontar, rememorar e transformar as experiências de vida do ser humano. Dessa forma, a obra musealizada Marabá, de Rodolpho Amoedo, à medida que uma personagem circunscrita num contexto, com todas as suas idiossincrasias socioculturais, econômicas e políticas, agrega em si inscrições do imaginário ideológico latente no Brasil oitocentista. Assim, a título de reflexão despretensiosa, uma vez concebendo museu como fenômeno, a Museologia delineia seu espaço como campo de síntese e encontro entre tendências/perspectivas inter-, multi- e transdisciplinares, estreitando relações com Patrimônio, Comunicação e Educação.

Acerca da diversidade cultural e da quebra de paradigmas que as obras de arte podem suscitar, reiteram as autoras Reis e Pinheiro (2009, p.1) que o museu, frente às exigências contemporâneas da humanidade, reveste-se da necessidade do exercício de repensar sua identidade sociocultural

[...] estruturando-se como espaços de vida e não locus de contemplação, prazeres singulares particularizados e, possivelmente individualizados. Sabe-se que não será de fora para dentro que se encontrarão suas possibilidades de transformação que, a nosso ver, se acham inscritas nesse "novo" e criativo processo. [...] que justifica sobremaneira sua própria razão de existir: uma prática educativa efetivamente pronta a acolher a todos em sua pluralidade e diversidade de saberes e condições sócio-econômico-culturais específicas e singulares $[\ldots]$

Com base nesse preâmbulo, o estudo sobre a sexualidade e a subjetividade que a envolve torna-se relevante, por ser um dos pontos nevrálgicos nas relações sociais, uma vez que os conceitos padronizadores do comportamento e até mesmo da subjetividade humana são permeados pelo "certo" e o "errado", advindos dos determinismos sociais. “[...] Entende-se a relação sexualidade e dimensões socioculturais, em meio à determinada formação social, como dominada pelo poder do capital que se estende desde um longo período histórico e cujo fim ainda não está à vista [...].” (REIS, 2012, p.103). 
Partindo de tais pressupostos teóricos, este estudo justifica-se pela intencionalidade de desvelar a linguagem simbólica flagrante no corpo musealizado de Marabá, a partir de memórias histórico-culturais, no que concerne especificamente à intrínseca relação entre ser, saber e poder, para refletir acerca de questões que apontam o corpo sexualizado da mestiça como marca do patrimônio identitário da cultura brasileira.

Cumpre esclarecer que não se tem a pretensão de enquadrar esta tese como estudo de gênero, na medida em que o que se focaliza é a educação para a sexualidade, construída e reconstruída nos tempos atuais por uma imagem de uma mulher e mestiça trazida dos oitocentos pela arte musealizada em que se articula patrimônio e identidade, inclusão e exclusão e a interculturalidade como possibilidade de rompimento das amarras sexistas.

Na construção da história humana, relevante papel exerce a educação no que diz respeito à aprendizagem sobre o corpo como veio de leitura do universo intercultural, pois, “[...] assim como a inteligência, a sexualidade atua como patrimônio de um povo, [uma vez que] ela será construída a partir das possibilidades individuais e de sua interação com o meio e a cultura." (BRASIL, 1998, p.296).

Os conflitos vivenciados no Brasil, como sendo consequência de uma sociedade híbrida, principalmente por suas contingências históricas, sinalizam áreas e temáticas diversas, que vão da exclusão de classe àquelas que se referem à etnia, raça, geração, sexo e gênero, passando também pelo acesso à informação.

Em face dessas contradições, urgem medidas no sentido de investir e recuperar estudos sobre a correlação entre patrimônio e sexualidade, de modo a acurar qual é o grau de interferência das implicações etnográficas marcantes no final do século XIX que serviram de inspiração para alicerçar a leitura que Rodolpho Amoedo fez do fenômeno da mestiçagem e de que maneira essa visão artística retrata a sexualidade na cultura brasileira com maior ou menor expressividade espácio-temporal.

Dessa forma, falar de sexualidade e identidade significa também falar de repressão, poder, preconceito, interdição do corpo, desejo, paixão, prazer, vida, morte, controle, gênero, pecado, “opção" sexual, construção de papéis sexuais, enfim, de todas as representações socioculturais que giram em torno dela na sociedade (TOSTES DE ALMEIDA, 2008).

Com o propósito de conferir cientificidade à discussão, adotaram-se os seguintes objetivos gerais: 
- analisar criticamente a obra Marabá, de Rodolpho Amoedo, a partir da leitura do corpo feminino sexualizado como território de representações simbólicas do imaginário sociocultural brasileiro do século XIX, a fim de compreender de que modo as relações entre educação, sexualidade e interculturalidade se projetam sobre os sujeitos contemporâneos.

$\mathrm{Na}$ perspectiva de direcionar as ações para o alcance do objetivo geral, delinearam-se estes objetivos específicos:

- realizar a leitura do corpo sexualizado de "Marabá", partindo do etnoconhecimento para o etnorreconhecimento;

- analisar como a ideia de mestiçagem torna-se um patrimônio simbólico do povo brasileiro.

No panorama da pesquisa qualitativa, optou-se pela adoção do Estudo de Caso Único, numa concepção fundamentada em Stake (2007), na perspectiva de abordar profundamente, retratar, compreender, interpretar e analisar, sob a lente do estudo de Museu e Museologia, o corpo como patrimônio em Marabá, de Rodolpho Amoedo, deslindando-se os índices e símbolos que a leitura semiótica da interculturalidade oitocentista capturada na obra musealizada pode suscitar no leitor contemporâneo e, por conseguinte, educá-lo para esse "olhar” sensível.

Incorporou-se, ao procedimento metodológico, a técnica de Grupos Focais (CRUZ NETO; MOREIRA; SUCENA, 2002), no momento em que a pesquisadora imergiu no campo da Educação com os professores em formação do $2^{\circ}$ Período (posteriormente $3^{\circ}$ ) do Curso de Pedagogia, da Faculdade de Educação e Tecnologia do Rio de Janeiro (FAETERJ), Itaperuna-RJ. A escolha pelos GF se deu por se tratar de uma técnica que emprega uma práxis analítica, a qual concilia sua aplicabilidade teórica à pesquisa de cunho descritivo-analítico; ainda, cabe evidenciar sua utilização como técnica de prestígio, com destaque metodológico, no cenário da pesquisa social.

Pesquisa de cunho qualitativo, de caráter descritivo-analítico; elegeu-se o Estudo de Caso Único como abordagem que norteará a investigação (STAKE, 2007), por se entender que se está diante de uma proposta conceitual sólida e uma orientação metodológica coerente, através da qual se busca a possibilidade de se acompanhar atentamente o fluxo de acontecimentos na trajetória da pesquisa. Ainda, na perspectiva de se adotar um aporte que transcendesse à mera obtenção dos dados, incorporou-se a técnica de "Grupos Focais" (GF) ao escopo metodológico deste estudo, no campo da Educação, tendo como universo amostral professores em formação do Curso de 
Pedagogia, com o propósito de se garantir o captar e o desvelar da problemática da realidade observada.

A técnica de GF, de fato, constituiu-se um alicerce que se aliou ao Estudo de Caso para prover à pesquisa melhor organização, entendimento e aplicabilidade. Importa ainda explicitar, no tocante aos sujeitos da pesquisa - protagonistas do processo de coleta de dados -, que participaram a pesquisadora e 12 estudantes (dos sexos: masculino e feminino), na faixa etária entre 18 e 30 anos, do curso de Pedagogia da Faculdade de Educação Tecnológica de Itaperuna (FAETERJ), que atuaram como integrantes do chamado Grupo Focal.

\section{Buscar-se-á suporte para a análise metodológica pretendida na semiótica} peirciana, cujo mote de leitura será orientado pelo seguinte itinerário: potencialidade sígnica no discurso literário, triangulação dos dados e representação simbólica dos mesmos. Nesta fase da pesquisa, interessa à pesquisadora o deslindar dos ícones e enigmas contidos na criação artística de Marabá de Rodolpho Amoedo, sob a égide da leiturização possibilitada pela semiose emanada da obra, a partir do ponto vista da pesquisadora.

Desenvolve-se, assim, a análise dos constituintes sígnicos mais significativos para o entendimento do texto, sob a perspectiva da semiótica peirciana, tomando-se como âncora para a leiturização a tríade ícone-índice-símbolo, devidamente comprovada por demonstrativos e consubstanciada pelas teorizações pertinentes. Assevera-se, em tempo, que a proposta de leitura em questão servirá tão-somente de deflagrar a interpretação da obra musealizada Marabá, no âmbito da Museologia e Patrimônio.

Para assegurar o acesso aos dados que comprovem os estágios de potencialidade da linguagem literária, será tomada de empréstimo da semiótica de Peirce, a tríade que protagonizará o itinerário da leitura será constituída de ícone, índice e símbolo, respeitadas as características de cada elemento, com o propósito de que essas três espécies de relações consubstanciem as etapas em que, em Marabá, o signo possa estar para o objeto (a obra em si), como signo desse objeto.

Como as incursões teóricas advindas da semiótica peirciana são assaz complexas, para dar conta de ler sob o viés da tricotomia há pouco mencionada, o estudo em tela se conduzirá, a priori, pela estrutura mais elementar do postulado de Peirce, qual seja: 


\section{Função Mediadora}
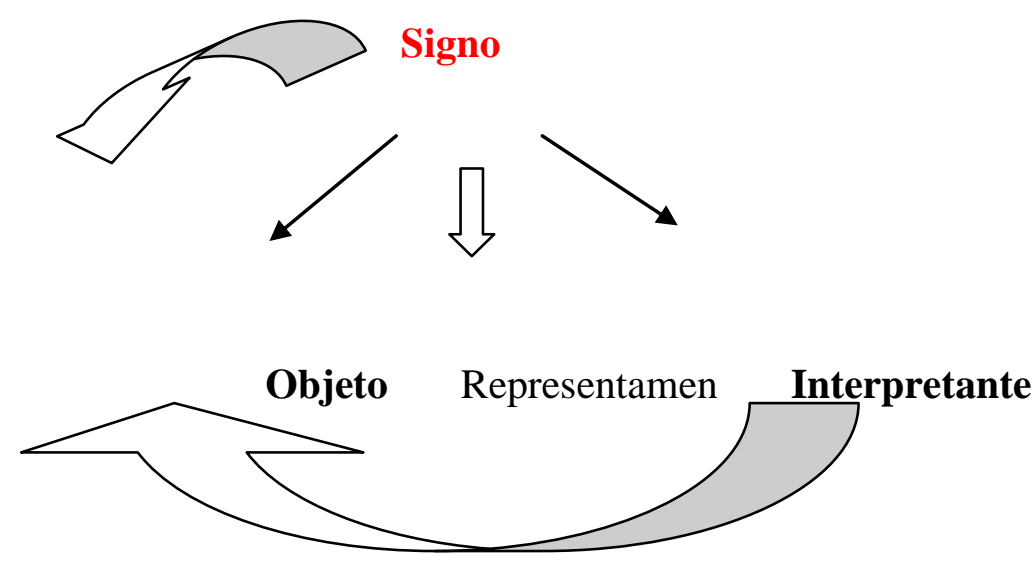

No ensejo de dar pertencimento aos constituintes supracitados, foi elaborado o esquema a seguir, a partir dos elementos da pesquisa em tela:
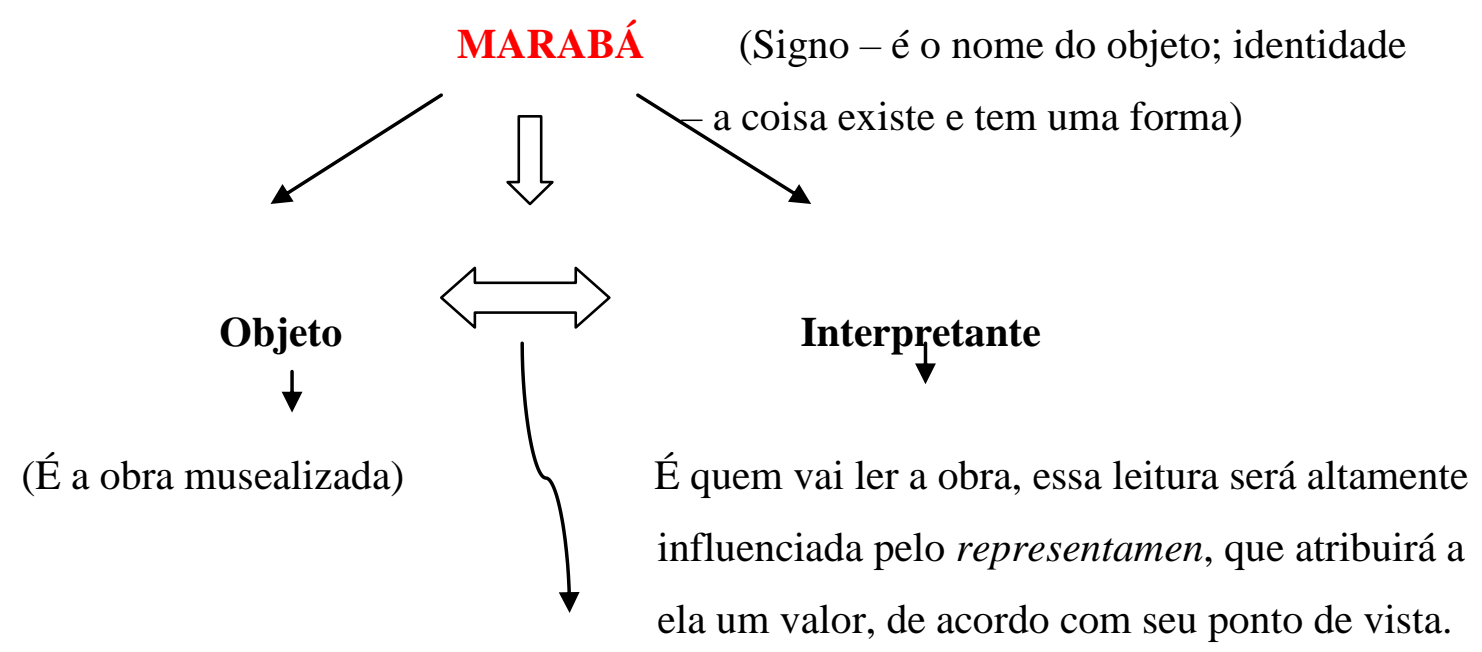

Isso é Semiose; a criação artística é aberta; a leitura será modificada tantas e quantas forem às vezes que alguém propuser uma nova perspectiva de análise.

Nessa linha de pensamento, por meio de Peirce e sua visão fenomenológica, pode-se apreciar qualquer gênero textual que ofereça maior condição de interpretabilidade, pois, partindo-se do pressuposto de que o exame pela relação triádica do signo permite demonstrar que o pensamento é constructo do diálogo com outros pensamentos, confirma-se que o interpretar instaura uma continuidade ad infinitum. 
Um signo, ou representamen, é aquilo que, sob certo aspecto ou modo, representa algo para alguém. Dirige-se a alguém, isto é, cria na mente dessa pessoa um signo equivalente, ou talvez, um signo mais desenvolvido. Ao signo assim criado, denomino interpretante do primeiro signo. O signo representa alguma coisa, seu objeto. Representa esse objeto não em todos os aspectos, mas com referência a um tipo de ideia que eu, por conseguinte, denominei fundamento do representamen (SANTAELLA, 1983, p.23).

Nesse contexto, o nome "Marabá" remete ao signo ou representamen do contexto do qual a obra (objeto) advém, ou seja, traz em seu bojo todas as matrizes interculturais que perpassam a criação artística e dialogam com o interpretante. Daí o entendimento de que as ideias trazidas por Santaella (1983) corroboram que o engendramento lógico é decorrente do contato entre signo, objeto e interpretante, uma vez que se colocam em relevo as relações de determinação tanto do signo pelo objeto quanto do interpretante pelo signo. O signo aparece, na verdade, exercendo função mediadora entre objeto e interpretante, sendo esse interpretante algo criado pelo próprio signo, na medida em que as associações com base na busca de entendimento ou mesmo no estabelecimento das representações simbólicas são realizadas.

\section{CORPO E IDENTIDADE SOCIOCULTURAL}

Na presente pesquisa, apresenta-se o corpo como patrimônio pessoal, cultural e social, no palco da Museologia e do Patrimônio, com o propósito de compreender de que forma o corpo humano retratado na obra musealizada pode atuar como depositário das implicações sociais e culturais de uma dada época. Trata-se de um corpo simbólico, motivo pelo qual se pautará na leitura da produção imagética de Marabá, arte pictórica de Rodolpho Amoedo, século XIX, a fim de investigar de que maneira a figura humana do corpo como fenômeno cultural em suas diferentes representações não neutras, valores e relações de poder presentes no Brasil oitocentista têm seu nascedouro no bojo das demandas sociais, culturais políticas, nas quais se incluem as demandas da sexualidade humana.

Através da arte acadêmica, ancorado na perspectiva intercultural, Amoedo retrata o simbólico flagrante na expressão artística da mestiçagem, fato que constitui o traço identitário do corpo cultural e sexual brasileiro. Urge elucidar que o enfoque será direcionado para a questão da sexualidade, e não do gênero, uma vez que essa distinção 
epistemológica não interessa ao estudo em apreço, por não servir para elucidar as discussões pretendidas.

Na trama identitária, além de uma organização biológica, o corpo revela o que temos de mais particular, a singularidade, entretanto, paradoxalmente, constitui-se como um objeto particular e social, por exibir as dimensões identitárias pessoais, bem como socioculturais, simultaneamente. Nesta esteira, atento ao princípio Habeas corpus3, Jeudy (2002, p.14) salienta que

[...] a ideia comum de que, se nosso corpo nos pertence, isso ocorre na medida em que somos sujeitos do objeto que ele representa, o que faz persistir uma dúvida acerca da realidade. Será que experimentamos essa realidade quando nosso corpo é tratado como objeto ou quando cremos ser o sujeito das sensações que o animam?

Numa teia de configuração indissociável, pensar o corpo como algo de pertencimento exclusivamente pessoal é desconsiderar suas implicações por inserção num contexto cultural e social e, principalmente, educativo. A título de reflexão, Freud (1988, p.39) postula que “o eu é, primeiro e, acima de tudo, um eu corporal; não é simplesmente uma entidade de superfície, mas é, ele próprio, a projeção de uma superfície”. Na perspectiva do real do corpo (organismo) e do seu imaginário (constitutivo pessoal, cultural e social), o sujeito se pensa existindo num corpo, porque o eu é por si só já corporal.

Trazendo essa marca identitária para o campo simbólico, Bourdieu (2008) caracteriza o corpo como lugar de categorização social, como superfície de inscrição de marcas distintivas de gênero, de raça, de classe, de poder. Sendo a premissa verdadeira, pensar o corpo sob esse prisma possibilita apresentar o "eu" e o "outro" através do nu artístico de "Marabá", de modo a permitir o não posicionamento do corpo como um objeto neutro, mas como uma linha de força que conduz a narrativa erótica e sensual pictórica a uma cumplicidade tangível entre o artista - corpo nu - e o observador. "A obra de arte considerada enquanto bem simbólico não existe como tal a não ser para

${ }^{3}$ Habeas corpus significa "que tenhas o teu corpo", e é uma expressão originária do latim. Habeas corpus é uma medida jurídica para proteger indivíduos que estão tendo sua liberdade infringida, é um direito do cidadão, e está na Constituição brasileira. "Nasce com formato próximo ao atual na Magna Carta de João sem Terra em 1215, consagrando-se no Habeas Corpus Act de 1679. No Brasil, surge expressamente no Código de processo Criminal de 1838. Hoje, a Constituição Federal, em seu art. 5. ${ }^{\circ}$, LXVIII prevê que conceder-se-á habeas corpus sempre que alguém sofre ou se achar ameaçado de sofrer violência ou coação em sua liberdade de locomoção, por ilegalidade ou abuso de poder." (FULLER; JUNQUEIRA; MACHADO, 2013, p.307). 
quem detenha os meios de apropriar-se dela, ou seja, de decifrá-la." (BOURDIEU; DARBEL, 2007, p.71).

Na perspectiva de Certeau (1982, p.172), “[...] o corpo é um código à espera de ser decifrado [...]; cada sociedade tem seu corpo, assim como ela tem sua língua”. Daí a conclusão de que não existe um paradigma corporal único, nem corpo igual, nem diferente, mas semelhantes, cada qual com suas particularidades, variáveis culturais assimiláveis para cada indivíduo, época e sociedade.

A pintura em tela "Marabá" de Amoedo tem sua origem na poesia "Marabá" de Gonçalves Dias, publicada em 1851 na obra Últimos Cantos, cujas abordagens épicas transbordavam suas inquietações acerca da importância de lutar por preservação e manutenção das origens, dos valores fundantes do Brasil, que se assentam na raça, costumes e paisagem, sem contar lutas, conquistas e dores emanadas da imbricada relação de mestiçagem.

Os corpos suscitados no imaginário literário, a partir da metade do século XIX, recebem variações na narrativa. Ao corpo nu feminino concedia-se a imagem da sensualidade, um corpo erótico que não excedesse aos preceitos da moral e ao masculino como símbolo da virilidade, da força e do belo.

As obras de Gonçalves Dias trazem uma trilogia, quase que indissociável como contextos-chave do começo do movimento literário romântico, por assim dizer, desvelando questões sobre a raça, o costume e a paisagem. Em suas produções os corpos eram quase sempre apresentados numa paisagem tropical e esplendorosa, marcando a indígena e o ambiente. Embora de modo subjacente, situava a raça e o gênero num contorno de sensualidade, fragilidade, sobretudo sem identidade, fruto da época e, por conseguinte, de seus conflitos.

Através da narrativa etnográfica, a literatura brasileira transporta para toda Europa um olhar sobre o exótico, favorecendo a construção do imaginário acerca da América em descoberta. Na obra "Iracema", já citada anteriormente, o autor a estigmatizou como a índia "virgem dos lábios de mel", destacando atributos de inocência e fertilidade. Em tom de poesia, a virgindade enaltece a sensualidade com doçura atribuída ao corpo da mulher índia. Como heroína tipicamente romântica, Iracema é associada a elementos da fauna e da flora brasileiras que auxiliam a formar uma imagem idealizada, enobrecedora. Aliás, a força imagética e simbólica da personagem começa pelo próprio nome, já que se tem em "Iracema" um anagrama de 
"América", apresentando-se, pois, como ampliação de uma sintomatologia local globalizadora.

Apesar de Gonçalves Dias e Amoedo trazerem os silvícolas como personagens fulcrais em suas obras, diferenciam-se na ênfase e contextualização ao indianismo romântico e ao indianismo acadêmico. Amoedo não se posicionava em colisão direta com o indianismo acadêmico, porque nele estava inserido, mas com maestria e muito talento, ressignificava elementos constitutivos do indianismo clássico, de maneira a possibilitar caminhos para um olhar crítico à realidade social e política do final do século XIX que, apesar de proclamar proteção aos índios e mestiços, as políticas indigenistas encolhiam seus espaços, o que favorecia sua exclusão e discriminação.

Em tempos de fragilidade e decadência do império no Brasil, a figura do índio, do escravo, enfim, a do mestiço, passou a simbolizar uma herança ruim para a elite, uma vez que o país abolia a escravidão de seus negros úteis e abria o caminho para uma nação cidadã. Neste contexto, os artistas da época criavam e apresentavam seus personagens, como "Marabá", "A Escrava Isaura", "O Mulato", "O Carvoeiro", "O Derrubador", que, num misto de fantasia e realidade, exteriorizavam a complexidade social na qual o Brasil estava imerso.

O corpo indígena foi o ícone simbólico do projeto nacionalista até os primeiros sinais de falência da monarquia. Como salienta Migliaccio (2001), Amoedo é um artista de reflexão, ligado à filosofia e à literatura, mas traduz sempre a reflexão. Nesse sentido, Costa (2013) acrescenta que Amoedo, apesar de procurar se adaptar às novas exigências da política cultural do império, uma vez que seus trabalhos eram patrocinados pela monarquia, buscava introduzir uma nova perspectiva sobre o corpo indígena.

Amoedo permanece enraizado na cultura acadêmica do século XIX, contudo, dono de um expressivo talento para desenho, de traços quase que impressionistas marcados também pelas cores sutis e, por vezes arrojados, procura traduzir através de suas obras o delicado momento nos quais os indígenas eram protagonistas e antagonistas nos palcos do poder oitocentista.

\section{COMPREENSÃO, INTERPRETAÇÃO E ANÁLISE DOS DADOS: UMA ABORDAGEM SEMIÓTICA}


Na figura imagética em tela de Rodolpho Amoedo, tomando como ponto de partida a hipótese de que o corpo sexualizado, musealizado e mestiço da Marabá de Gonçalves Dias é o simbolismo da valorização das dificuldades, do sofrimento, sobretudo da exclusão /inclusão ${ }^{4}$ mais incisiva do índio e mais timidamente do negro na matriz do povo brasileiro e, na Marabá de Rodolpho Amoedo, aparece uma mestiça reconhecida como tal e que tem dificuldades em pertencer à sociedade brasileira oitocentista.

Reitera-se o encaminhamento de um desenho metodológico alicerçado nos referenciais teóricos da semiótica peirciana, como possibilidade pragmática de contextualizar cenários da vida real e suas interfaces com o simbólico-imaginário, numa obra ficcional, para, a partir dela, dar continuidade ao processo de análise, em cujo momento entram as narrativas do Grupo Focal.

À luz da teoria de Peirce (1974), entende-se de que maneira os elementos se atualizam ao representamen (aquilo que representa todo o percurso de um determinado interpretante, ou seja, o resultado alcançado mediante o processo de interação das categorias cenopitagóricas - primeiridade, secundidade e terceiridade), saber:

- $\quad$ primeiridade - é a fonte primitiva, indefinida, fresca, espontânea; é, portanto, o momento da sensação imediata;

- $\quad$ secundidade - envolve o momento do conflito (resistência, reação, compulsão, interrupção, intrusão) diante do objeto experienciado fenomenologicamente;

- $\quad$ terceiridade - trata-se de uma espécie de lei de probabilidades em busca de uma interpretação racional acerca do fenômeno experienciado.

Assim, esses elementos, de natureza tricotômica, engendrados em franca interação semiótica, atingem o estágio da concepção simbólica, que poderá desencadear uma nova sequência cenopitagórica a partir de um novo ícone, agora degenerado, constituindo, assim, a autogeração de um outro representamen.

Logo, através da leitura pelo itinerário semiótico do interpretante sobre o "corpo feminino sexualizado de Marabá" na obra musealizada de Rodolpho Amoedo,

\footnotetext{
${ }^{4}$ Foucault, a partir do eixo genealógico, apresenta como base de tais reflexões o saber e suas implicações no jogo do poder: "[...] o poder é o que reprime a natureza, os indivíduos, os instintos, uma classe" (FOUCAULT, 2011, p.175). Acrescenta-se que, em a Microfísica do Poder, Foucault aborda postula que a noção de inclusão e exclusão confere relevância ao lugar do poder e/ou ao poder que ocupa microfisicamente os espaços.
} 
consideram-se contingências interdisciplinares e possibilidades educativas de compreensão do corpo como patrimônio pessoal, social e cultural.

Enveredar pelos enigmas de Marabá é possibilitar uma viagem em direção às origens constitutivas brasileiras e trazer à tona perguntas originais: a) "quem foi o Outro que nos designou desde o começo?", b) “que corpo temos desde de que o Outro nos designou?".

Ler o corpo nu e sexualizado da Marabá de Amoedo oportuniza novos olhares reflexivos acerca do aparato social e das relações de poder que intercruzavam e constituem, muitas vezes velado, o modus vivendi dos corpos do século XIX, pensados aqui, pelas abordagens plurissignificativas, a partir do olhar do interpretante permitido pela semiótica peirciana.

Nas trilhas do ícone degenerado, Amoedo faz uma releitura da poesia de Gonçalves Dias. Além de caracterizá-la pictoricamente, modifica algumas características da personagem, como a cor dos olhos, a cor dos cabelos, sobretudo apresenta Marabá despida, nua, detalhe que em momento algum foi explicitado na poesia.

No palco da arte, a sensibilidade é o ingrediente que explicita da melhor maneira a categoria peirciana da primeiridade (diz respeito à qualidade, à percepção, ao impacto diante do que se vê), desencadeamento de sensações, aflições, angústias, conflitos, próprios da secundidade (aspecto do singular- sentimento) até atingir a terceiridade (generalidade, possibilitando a leitura numa visão de senso comum), que consubstanciam as relações entre o signo, objeto e o interpretante.

A primeiridade não se encaixa numa categoria conceitual, mas sim relacional, consentindo um fluxo comunicacional e direções semióticas em múltiplas áreas do conhecimento. No caso de Marabá, o signo na primeiridade é caracteristicamente região do ícone, ligado ao momento de aflição, angústia, indagação existencial, na tentativa de resgatar o que não sabe se perdeu. Traduz a dor do vazio existencial na obra genuína, “a poesia de Gonçalves Dias".

Amoedo, todavia, na recriação de Marabá, novo signo ou ícone degenerado, constrói a imagem de uma mulher que, mesmo mergulhada em suas dores existenciais, está nua, como se não tivesse medo, nem vergonha de ser quem é, ou seja, pronta para enfrentar a vida! Assim, os artistas que se propõem à releitura de outros trabalhos, como no caso de Amoedo com relação à Marabá de Gonçalves Dias, produzem signos 
indiciais e simbólicos durante o processo de construção sígnica, sendo a obra o fruto de uma ordem da primeiridade em distintos níveis.

"Se a secundidade é uma relação existencial, o índice é genuíno. Se a secundidade é uma referência, o índice é degenerado". (NÖTH; SANTAELLA, 1998, p.148). Partindo desse postulado, Marabá de Amoedo se apresenta como índice degenerado, porque nasce de uma referência de uma índia mestiça que já fora retratada, cujas características apresentadas na matriz poética são relidas e transformadas. $\mathrm{Na}$ imagem em questão, Amoedo evidencia conflitos fundamentais na hierarquização de gêneros, característica própria da pintura acadêmica, que retrata a oscilação entre o nu e a pintura histórica em posição épica.

A terceiridade simbólica degenerada em relação à primeiridade é a pintura simbolista, na medida em que os signos mantêm uma relação de similaridade com os objetos (NÖTH; SANTAELLA, 1998). Nesse pressuposto, Amoedo traz no nu de Marabá a chave da alteridade sensual, desarticulada do imaginário primário, inscrevendo no corpo de outra etnia (ou raça, como se tratava nos oitocentos), de modo que a nudez não fosse algo ou um fato inconveniente e que incomodasse à elite da corte e ao público, mas que traduzisse aspráticas discursivas de hegemonia social.

Observa-se que, na pele embranquecida de Marabá, Amoedo manteve a originalidade da poesia, trazendo o sentido de manutenção da integridade social da raça dominante, resguardando-se à mestiça o atributo da sensualidade, exposta no corpo despido, bem como uma ideia de corpo sem pudor, pronto para o que der e vier, em oposição à repressão dos corpos e da sexualidade que havia no século XIX.

Retomando o sentido primeiro do ícone, Marabá não foi aceita por ter um corpo mestiço, entretanto registrou-se, através do seu corpo nu, um olhar sobre uma identidade feminina da brasileira vista nos moldes do século XIX.

As descrições étnicas correspondem à personificação de uma mestiça (cabelos negros, olhos escuros, pele de cor branca, como referenciada no parágrafo anterior) trazem também, além do corpo nu, outros índices relevantes à representação pictórica, como corpo assimétrico em seus contornos na composição corpórea: pés com traços finos, perfeitos e delicados, pernas longas com joelhos e quadril grandes e desproporcionais, seios pequenos, arredondados, rijos e lábios carnudos.

Os índices descritos acima provocam um deslocamento do sentido indianista apresentado no poema de Gonçalves Dias para uma atmosfera erótica na pintura de 
Amoedo, que instiga ao pensar em direção ao processo de reconstrução de imagem a partir dos discursos ideológicos.

A descrição realista de Amoedo no corpo de Marabá trazia um discurso de pertença sociocultural do período dos oitocentos, indicando uma imperceptível mudança de foco no que tange ao destaque dos elementos raciais na constituição étnica brasileira, diminuindo a ênfase à figura indígena, em destaque até então como um ícone genuinamente brasileiro, e, portanto, símbolo identitário do Brasil, fazendo emergir sutilmente a figura do mestiço resultante da miscigenação racial brasileira, de modo a situar o produto dessa mistura de raças, a priori, branco, negro e índio, como o verdadeiro biótipo do corpo brasileiro.

No corpo nu da Marabá de Amoedo, outro índice capturado foram as pernas e pés, que, segundo Chevalier e Gheerbrant (2003, p.710, grifo nosso), apresentam-se como "[...] um símbolo de vínculo social. Permite as aproximações, facilita os contatos, suprime as distâncias. Reveste-se, portanto, de importância social”.

Para os referidos autores, o pé, prolongando a perna, tem simbologia complementar:

[...] a perna cria os laços sociais, o pé é deles o senhor e a chave. Por extensão, a perna está para o corpo social como o pênis para o corpo humano: é o instrumento do parentesco uterino e das relações sociais, como o pênis é o instrumento da consanguinidade. A perna, como o membro viril, é símbolo de vida: desnudar a perna significa mostrar o poder e a virilidade. (CHEVALIER; GHEERBRANT, 2003, p.710).

Seguindo tal pressuposto, submetendo-se os pés de Marabá à lente semiótica dos autores aqui referenciados, a observação como interpretante/ interpretâmen desencadeia uma conexão do pé, de origem europeia, pelas características e formatos delicados que foram observados, como a chave de entrada, a conquista deste território: entrou pelos pés que aqui foram colocados! As pernas delicadas e longas, como símbolo de aproximação e estabelecimento de vínculos ou relações sociais duradouros e profundos, ou seja, o pé, como chave de entrada, marcou território e disse a que veio.

O índice coxas, ainda na visão de Mendonça (2004, p.9), “[...] evoca a adolescência e as passagens iniciáticas do amadurecimento que preparam para a experiência sexual, para a reprodução, para a entrada na idade adulta [...]". O que se pode observar, na figura imagética de Marabá de Amoedo, é que as coxas são longas e se encontram deitadas, em posição de preservação da intimidade, da sexualidade, o que 
poderia representar que "ser livre em relação aos prazeres é não estar a seu serviço, é não ser seu escravo.” (FOUCAULT, 2003, p.74).

A relação apresentada por Mendonça (2004) entre as coxas como preparação para a experiência sexual e a posição das pernas, sobrepostas e fechadas, pintadas por Amoedo em Marabá, dá pistas de uma reserva em relação à sexualidade, por vezes apontada na história dos oitocentos, não com o sentido de prazer, mas como instrumento de controle, dominação e usurpação do desejo de sentir, imbricado nas redes dos discursos científicos, religiosos, econômicos, sobretudo ideológicos, do saber e do poder sobre uma nação em constituição.

[...] a sexualidade é o nome dado a um dispositivo histórico [...] à grande rede de superfície em que a estimulação dos corpos, a intensificação dos prazeres, a incitação ao discurso, a formação dos conhecimentos, o reforço dos controles, das resistências, encadeiam-se uns aos outros, segundo algumas estratégias de saber e poder. (FOUCAULT, 1993, p.100).

Uma vez lidos como índices, os seios aparecem, na figura imagética da Marabá de Amoedo, apresentados em formato arredondado, firme e pequeno, sendo emoldurado por uma alva tez. "Seios são símbolos de proteção, sobretudo símbolo da maternidade, de suavidade, de segurança, de recursos. São ligados à fecundidade e ao leite, sendo o primeiro alimento; são associados às imagens de intimidade, de oferenda, de dádiva e de refúgio" (CHEVALIER; GHEERBRANT, 2003, p.820). A partir da visão dos autores supramencionados, os seios são fonte de alimento e símbolo da maternidade, portanto, nos seios de Marabá de Amoedo, estaria a presença e a marca da matriz étnica brasileira, que, interpretados (os seios) aos olhos da semiótica peirciana, revela-se à pesquisadora um apontamento para a matriz europeia da mestiçagem brasileira como aquela que faz nascer, que dá "segurança" e provê recursos, por isso o formato dos seios se assemelha ao do padrão feminino europeu e não ao da indígena, muito menos ao da africana.

Já na perspectiva da Psicanálise freudiana, o sentido simbólico da maternidade atribuída aos seios é ampliado, ligando-os à fonte de manutenção da vida pelo prazer, atribuindo-lhes, assim, um valor simbólico da erotização singular feminina, que assume também, na visão lacaniana, um valor simbólico da potência materna no processo de identificação.

"Pintar a superfície do corpo é escolher um modo singular de exibição; é, conforme cada um imagina, encontrar o meio de exprimir de si mesmo o que seduzirá o 
Outro" (JEUDY, 2002, p.88). E é nesse sentido que o rosto da Marabá de Amoedo manifesta-se com lábios carnudos, exóticos e sensuais da negra entregues à mestiça, à mulata, por fim, à mulher brasileira, "a fim de reforçar o erotismo da construção": “lábios grossos e úmidos pedem o beijo" (DUARTE, 2009, p.67).

Nesta mesma abordagem, captura-se a nudez do corpo da Marabá de Amoedo como um índice em destaque, tendo em vista que, em momento algum, a Marabá da poesia de Gonçalves Dias, na qual a Marabá de Amoedo tem sua matriz, relata estar nua. Amoedo traz sua Marabá, além de nua, revestida da sensualidade da mulher mestiça brasileira.

\section{PARTICIPAÇÃO DO GRUPO FOCAL}

Uma vez realizada a análise do conteúdo extraído do discurso dos respondentes do Grupo Focal, no intento de promover a educação do corpo pelo patrimônio em tempos hodiernos, por intermédio da leitura da obra musealizada "Marabá" de Rodolpho Amoedo (1882), ratificou-se que, mesmo para estudantes de graduação com formação cultural pouco consistente e que residem em localidades que se distanciem consideravelmente dos grandes centros urbanos, como no caso de Itaperuna (noroeste do estado do Rio de Janeiro), à luz de um referencial teórico-metodológico consistente e adequado, é possível desmitificar o pensamento antiquado de museu como lugar de se guardar coisa antiga e ressignificar seu conceito, orientando para que seja visto como fenômeno, que, com base em preceitos da semiótica peirciana, pôde ter sua fenomenologia interpretada, a ponto de desencadear semioses ilimitadas.

Ainda, no desenvolver desta análise, que se constituiu a interpretação analítica do discurso emanado das reflexões críticas dos protagonistas que compuseram o Grupo Focal, cabe contemplar o entrelace desse discurso com a Leitura dos Índices desvendados no Ícone Pictórico Marabá de Rodolpho Amoedo pela pesquisadora do estudo, com o propósito de promover a educação do corpo pelo patrimônio na contemporaneidade, no viés da Semiótica peirciana (referencial metodológico da pesquisa), objetivando prover à investigação a acreditação que lhe é necessária, corroborando a articulação da teoria com a prática, pontuando a veracidade, a fidedignidade e a confiabilidade - fundamentais à proposta do Trabalho Científico em questão. E, nesse contexto, ensejou-se a premência de apontar os referidos índices através do quadro desenhado abaixo. 
Em que medida o corpo nu feminino e mestiço flagrante na obra musealizada "Marabá", de Rodolpho Amoedo, pode ser interpretado trazendo à tona quando analisadas a partir das representações simbólicas do Brasil oitocentista e sua ressonância na cultura contemporânea?

Verificou-se, com base na análise dos dados extraídos do discurso dos respondentes do Grupo Focal, que tudo é educação, não existe formal e não formal tudo é educação, tudo é sistematizado no seu dia a dia. Assim, o elemento que balizou este estudo foi inspirado em questionamentos acerca de: como a educação transforma?

Se ela é sempre transformadora, entende-se que a intensidade de transformação dela vai depender exatamente do que o Foucault assevera, como instituintes que estão numa sociedade que quer transformar ou não, onde estão os consumidores, e, se se tãosomente consumidor, não precisa haver educação que desenvolva o senso crítico.

Adentrando-se na comparação entre os olhares da pesquisadora e dos respondentes do Grupo Focal, ficaram evidentes que ambos captaram os mesmos índices em relação ao corpo tomado como ícone degenerado, destoando apenas quanto ao modo de se pronunciarem. Os estudantes foram capazes, mediante a apresentação e estudo do poema "Marabá" de Gonçalves Dias (1851) e da criação pictorial "Marabá" de Rodolpho Amoedo, de identificar os mesmos traços semelhantes e diferentes que foram destacados pela pesquisadora.

Também, ainda que de maneira mais simplista, devido à escassez de conceitos epistemológicos advindos das diversas áreas de conhecimento que fazem vizinhança com a Museologia e a Educação, emitir juízos interdisciplinares, com grau de criticidade considerável, se levada em consideração sua visão de mundo e, principalmente, o fato de não terem no cotidiano, tampouco na matriz curricular do Curso de Pedagogia, a cultura do Museu.

Como educar é um ato de transformação intra e interpessoal, emanou da interpretação crítico-reflexiva da pesquisadora em relação às falas dos respondentes do Grupo Focal que o museu, mesmo não tendo a função precípua de educar, educa. Mas, se ele educa, educa a quem? E como educa ao público que nele vai? O que uma simples obra de arte pode provocar? Da análise do corpus extraiu-se que o museu educa, sim, quando provoca num suposto público novos conhecimentos, a ponto de derrubar alguns paradigmas há muito instituídos e sedimentados no seu da sociedade como "verdade" e/ou ampliá-los para construir novos. 
Nessa (re)constituição de novos saberes, os estudantes da FAETERJ, ao desconstruírem aquela visão superada de que museu é apenas instituição onde se guardam coisas antigas, descortinaram novos olhares através da leitura crítica da obra "Marabá" de Rodolpho Amoedo, que os impulsionaram para além da imagem outrora visualizada, uma vez que os índices capturados revelaram vários constituintes da interculturalidade, os quais envolvem a obra desde a sua constituição como ícone degenerado (século XIX), portanto novo signo, até o diálogo com questões muito prementes na contemporaneidade (século XXI), como sexualidade, mestiçagem (etnia), comunicação, interculturalidade, em suma, educação para a diversidade.

Acerca do teor educativo inferido das opiniões dos respondentes do Grupo Focal, ficou evidenciado que o corpo da mulher, através da leitura dos índices em "Marabá" de Amoedo, é lugar de investimento do poder. Essa constatação tem seu nascedouro no fato de se compreender que a dimensão da sexualidade depende da ambiência cultural, tendo a ver com as diferentes culturas. Ela é, pois, interdisciplinar e intercultural. Por isso mesmo, em Marabá, os respondentes notaram que, como mulher mestiça de um Brasil oitocentista, foi impregnada das marcas identitárias que representavam o investimento do poder da época.

E, nos dias atuais, há 133 anos após a data de sua exposição em Paris, ainda suscita questões sobre o lugar das mulheres mestiças na vida cotidiana da sociedade deste Brasil contemporâneo, uma vez que perdura uma série de prescrições e enquadramentos comportamentais ditados pela máquina do poder vigente.

\section{CONSIDERAÇÕES FINAIS}

No estudo em tela, compreendeu-se o lugar da mestiçagem aliada à sexualidade como referência identitária do povo brasileiro, reconhecendo-a no corpo feminino sexualizado de Marabá de Amoedo, como um dos patrimônios simbólicos da nação brasileira. Como o tema é assaz complexo, recomenda-se ampliar as discussões, na medida em que a pesquisa atual não se propõe esgotar o tema.

A pesquisa constituiu uma oportunidade ímpar para se entrar no museu e, mais que "olhar", ver, através da obra musealizada "Marabá" de Amoedo, registros e deslocamentos da construção da história da nação brasileira, para sentir, de perto e na carne, como o corpo abriga resultados de aprendizagens e discursos de dominação e, sobretudo, como o corpo sexualizado feminino é idealizado, imaginado, visto e sentido, 
de tempo em tempo, de geração em geração, de século em século, como representante de uma ordem social através da qual as pessoas, em especial as mulheres, são utilizadas como instrumentos de manutenção do poder, ou seja, o corpo vem sendo o veículo que transporta toda a ideologia do capital.

Ao se reapresentar a obra musealizada "Marabá" (1882) de Rodolpho Amoedo aos respondentes do Grupo Focal, mediante uma série de reflexões educativas sobre a contextualização da obra, os estudantes de Pedagogia situam Marabá no centro das reflexões sobre o lugar do corpo mestiço sexualizado como um dos ícones do patrimônio identitário brasileiro.

Após análise dos dados emanados das falas dos respondentes do Grupo Focal, concluiu-se que o corpo feminino mestiço e sexualizado pode ser sugerido como patrimônio pessoal e sociocultural, uma vez que a mestiçagem aliada à sexualidade atuam como marcas identitárias comuns ao povo brasileiro, uma vez que o corpo mestiço é espaço limítrofe que abriga inscrições simbólicas suscetíveis a olhares plurissignificativos.

Mediante o exposto, comprova-se que o museu, como fenômeno social, não só presentifica, como também integra culturas, uma vez que uma obra musealizada, como no caso da Marabá de Rodolpho Amoedo, não se limita à circularidade temporal, mas ajuda a entender a passagem, o fluxo e o movimento dos seres humanos, portanto educa, numa linha de tempo tão perene, que concede imortalidade às obras e lhes deixam propensas a estágios de semioses e epifanias ilimitadas, conforme a capacidade de “olhar" lá dentro, "ver" e revelar aquelas experiências de vida apreendidas ao mundo. 


\section{SEXUALITY AS A PERSONAL AND CULTURAL HERITAGE: AN OPEN DOOR FOR AMOEDO OF MARABÁ TO CREATE THE MUSEUM AS EDUCATIONAL SPACE AND INTERCULTURAL}

ABSTRACT: This study had the motto critical-interpretative analysis of Marabá work of Rodolpfo Amoedo, focusing on understanding of how the sexualized female body added symbolic representations of the Brazilian socio-cultural imaginary of the nineteenth century with its projections and its consequences in the relations between education, sexuality and interculturalism in contemporary subjects. In this sense, the objective was to understand the role of imbricated sexuality miscegenation as builder of sexual subjects from the non-formal education held in museums as well as perform the reading of sexualized body "Marabá", based on the idea of a ethnoknowledge to the etnorreconhecimento, place, cross-culturally, the musealizada work "Marabá" in the context of body education for personal and socio-cultural heritage. Qualitative research, with the data collection technique "Focus Group". For analysis priority was given semiotic concepts to read the pictorial work "Marabá" Rodolpho Amoedo in Museum and Heritage field. It was concluded that by the respondents of the focus group, women's and sexualized body was recognized as personal and socio-cultural heritage, and miscegenation allied to sexuality as more forceful identity mark which gives the body mestizo the most genuine and relevant equity value of Brazilian nation.

KEYWORDS: Sexuality. Education. Museum. Heritage. Interculture.

\section{REFERÊNCIAS}

BACZKO, B. Imaginação social. In: . Memória e história. Enciclopédia

Einaudi. Lisboa: Imprensa Nacional e Casa da Moeda, 1984. v.1. p.33-45.

BRASIL. Secretaria de Educação Fundamental. Parâmetros Curriculares Nacionais: terceiro e quarto ciclos: apresentação dos temas transversais. Brasília, 1998.

BOURDIEU, P.A distinção: crítica social do julgamento. São Paulo: Edusp; Porto Alegre, RS: Zouk, 2008.

BOURDIEU, P.; DABEL, A. O amor pela arte: os museus de arte na Europa e seu público. 2.ed. Trad. Guilherme de Freitas Teixeira. São Paulo: EdUSP; Porto Alegre: Zouk, 2007.

CERTEAU, M. de. A escrita da história. Rio de Janeiro: Forense, 1982.

CRUZ NETO, O.; MOREIRA, M. R.; SUCENA, L. F. M. Grupos focais e pesquisa social qualitativa: o debate orientado como técnica de invetigação. 2002. Trabalho apresentado no XIII Encontro da Associação Brasileira de Estudos Populacionais. Ouro Preto, 2002.

CHEVALIER, J.; GHEERBRANT, A. Dicionário de símbolos: mitos, sonhos, costumes, gestos, formas, figuras, cores, números. 23.ed. Rio de Janeiro: José Olympio, 2003. 
COSTA, R. S. O corpo indígena ressignificado: Marabá e O último Tamoio de Rodolfo Amoedo e a retórica nacionalista do final do Segundo Império. 2013. $225 f$. Dissertação (Mestrado em História) - Instituto de Filosofia e Ciências Humanas, Universidade Estadual de Campinas, Campinas, 2013.

DIAS, G. Últimos Dias. 1851. Disponível em: <http://www.brasiliana.usp.br/bbd/handle/1918/00634600\#page/8/mode/1up>. Acesso em: 28 set. 2015.

DUARTE, E. de A. Mulheres marcadas: literatura, gênero, etnicidade. SCRIPTA, Belo Horizonte, v.13, n.25, p.63-78, jul./dez. 2009. Disponível em: <http://periodicos.pucminas.br/index.php/scripta/article/viewFile/4368/4513>. Acesso em: 25 fev. 2015.

FOUCAULT, P. M. História da sexualidade I: a vontade de saber. 21.ed. Rio de Janeiro: Graal, 2011.

2003.

História da sexualidade I: a vontade de saber. Rio de Janeiro: Edições Graal, Microfísica do poder. 4.ed. Rio de Janeiro: Graal, 1993.

FREUD, S. O id e o ego. In: Edição Standard Brasileira das Obras

Psicológicas Completas de Sigmund Freud. 2.ed. Rio de Janeiro: Imago, 1988. v.19. p. 13-72.

FULlER, P. H. A.; JUNQUEIRA, G. O. D.; MACHADO, A. C. C. Ações

impugnativas. In: Processo penal. 13.ed. São Paulo: ABDR, 2013.

JEUDY, H-P. O corpo como objeto de arte. Tradução de Tereza Lourenço. São Paulo: Liberdade, 2002.

MENDONÇA, J. G. R. O corpo e sua dimensão simbólica. Presença: Revista de Educação, Cultura e Meio Ambiente, v.8, n.29, maio 2004. Disponível em:

<http://www.revistapresenca.unir.br/artigos_presenca/presenca29_completa.pdf>. Acesso em: 8 mar. 2015.

MIGLIACCIO, L. R. A. O mestre, deveríamos acrescentar. In: BRASIL. Ministério da Cultura. Museu Nacional de Belas Artes. 30 mestres da Pintura no Brasil: Catálogo de Exposição. Rio de Janeiro: Pancrom, 2001. p.157-168.

NÖTH; W.; SANTAELLA, L. Imagem: Cognição, Semiotica, Mídia. São Paulo: Iluminuras, 1998.

PEIRCE, C. S. Charles S. Pierce. Tradução de Armando Mora D’Oliveira; Sergio Pomerang Blum ; Luís Henrique dos Santos. São Paulo: Abril Cultural, 1974. (Coleção Os Pensadores, 27).

REIS, M. A. de S. O corpo e o patrimônio cultura: o corpo fala, o corpo inventa, o corpo traduz: a construção discursiva da imagem sociocultural de si pelo(s) outro(s). In: ENCONTRO ANUAL DO SUBCOMITÊ REGIONAL DE MUSEOLOGIA PARA A 
AMÉRICA LATINA E O CARIBE, 21., 2012, Petrópolis. Anais... Petrópolis: ICOFOM LAM, 2012. p.219-230.

REIS, M. A. de S.; PINHEIRO, M. do R. Para uma pedagogia do museu: algumas reflexões. Museologia e Patrimônio, Rio de Janeiro, v.2, n.1, jan./jun. 2009.

Disponível em:

<http://revistamuseologiaepatrimonio.mast.br/index.php/ppgpmus/article/view/44/24>. Acesso em: 21 set. 2015.

SALTINI, C. J. P. Afetividade e inteligência. Rio de Janeiro: DP\&A, 1998.

SANTAELLA, L. O que é semiótica. São Paulo: Brasiliense, 1983.

SANTOS, M. C. T. M. Encontros museológicos: reflexões sobre a museologia, a educação e o museu. Rio de Janeiro: Minc/IPHAN/DEMU, 2008.

SCHEINER, T. C. M.; SOARES, B. C. B. A ascensão dos museus comunitários e os patrimônios 'comuns': um ensaio sobre a casa. 2010. Disponível em:

<http://enancib.ibict.br/index.php/enancib/xenancib/paper/viewFile/3311/2437>.

Acesso em: 5 de out. 2011.

STAKE, R. E. A arte da investigação como estudo de caso. Tradução de Ana Maria Chaves. Lisboa: Fundação Calouste Gulbenkian, 2007.

TOSTES DE ALMEIDA, M. Z. A sexualidade no cenário educacional: um olhar sobre a formação e a prática pedagógica. In: PROETNO: ETNOCONHECIMENTO PARA UM ETNORECONHECIMENTO, 2., 2008, Rio de Janeiro, Anais... Rio de Janeiro: UNIRIO, 2008. p.45-56. 